\title{
Regeneration of Road Users Using PreSiM Model
}

\author{
Mohamad Ghazali Masuri1, Akehsan Dahlan¹, \\ Ajau Danis², Khairil Anuar Md Isa² \\ ${ }^{1}$ Occupational Therapy Department, Faculty of Health Sciences, \\ ${ }^{2}$ Basic Sciences Department, Faculty of Health Sciences, \\ Universiti Teknologi MARA, Malaysia. \\ zalie222@gmail.com, akehsan@puncakalam.uitm.edu.my, \\ ajaudanis@puncakalam.uitm.edu.my, khairil_hpm@hotmail.com
}

\begin{abstract}
This study was involved in-one-to-one depth interview. Seven road users who had experienced road traffic accident were interviewed using semi-structured questionnaire. Data then analyzed using the Atlas.ti software. The themes that emerged shows that majority of the respondent agreed that to maintain driver's competency, there is a need to re-assess, and all qualified drivers and high-risk drivers may need to attend driving rehabilitation program in the future. The data was translated into a proposed model called PreSiM. This study concluded that human components have a high potential to be re-evaluated in the current licensing process.
\end{abstract}

Keywords: licensing, rehabilitation, maintenance, orientation

eISSN 2514-7528 @ 2018. The Authors. Published for AMER ABRA cE-Bs by e-International Publishing House, Ltd., UK. This is an open-access article under the CC BY-NC-ND license (http://creativecommons.org/licenses/bync-nd/4.0/). Peer-review under responsibility of AMER (Association of Malaysian Environment-Behaviour Researchers), ABRA (Association of Behavioural Researchers on Asians) and CE-Bs (Centre for EnvironmentBehaviour Studies), Faculty of Architecture, Planning \& Surveying, Universiti Teknologi MARA, Malaysia.

DOI: https://doi.org/10.21834/jabs.v3i10.312 


\subsection{Introduction}

Malaysia is currently experiencing rapid development on road transport system. The introduction of MRT project, for example, has significantly contributed to a short-term stress and disorientation among road users, especially in the city centre. The current development of public transport system in Malaysia involves rapid road design and construction either above or underground. The brisk development demands active participation from varieties of users including local community and also drivers. These processes were producing new environmental landscapes which currently improve the land value either in the rural or urban areas. The new road setting exposes additional cognitive and psychological challenges for road users. For example, road diversion and fixing new traffic light usually increasing time travel which requires for travel-rescheduling. Even though the 'stress' only occurs during the construction period, yet as a developing country, Malaysia needs a practical solution which will appreciate the future development.

The previous interview among educated young adult has shown that driving around Kuala Lumpur city centre can easily get them confused and disoriented by the road construction. Some of them were complaining that the assistive device for location and tracking were also unable to update the current route due to rapid development. They also need more time to familiarize themselves with the current landscape. In some extreme situation, they choose to violate the traffic rules and regulation such as making a U-turn at prohibited area. Almost the entire respondent agreed that, driving in Klang Valley significantly contribute to psychological stress. They were also agreed that 'this is the price of modernization.' This rapid development also made parallel with the national economic growth. The economy growth also has indirectly lead to the increasing rate of vehicles per capita in Malaysia. This can be observed through the increasing number of private vehicle ownership yet; this scenario will contribute to the greater risk of road traffic accident.

\subsection{Literature Review}

Road traffic accident (RTA) and human behavior are always tied together. Driving is usually involved complex physical and psychological components. According to (Shappell \& Weigmann, 2013) human factors or human error accounts for between $60 \%$ and $80 \%$ of all accidents and incidents occurred. Human errors are including the unbelted while driving, alcohol consumptions, violations, and others. This is supported by (Rakauskas, Ward, \& Gerberich, 2009) one of the factors that associated with the higher fatality crash rate is the attitude and psychological differences between rural and urban drivers in the perception of risk factors. For example, unbelted is one type of the risk-taking behaviour which may increase the crash fatality rate, especially among young adult.

With regards to risky driving behavior, there were lacks of an investigation conducted on safe attitudes locally. Currently, many kinds of literature claim that accident caused by human error yet, the limited evidence available to justify which human components are needed to be address. Previous study shows that, different factors such as personality (Chen, 2009), education level (Masuri et al., 2012), age/gender (Mohammadi, 2011), sociodemographic 
issues (Al-Naggar, Bobryshev, \& Mohd Noor, 2013), rural/urban location (Rakauskas, et al., 2009), socioeconomic status (Masuri, Isa, \& Tahir, 2012), body anthropometry (Pheasant, 1990) and living status (Al-Naggar, et al., 2013) brought significant effects on driving behavior. The demands of physical and psychological components usually varied from one driving activities and another. It is an intricate daily activity that involves active eye, hand, and foot coordination. (Masuri, Isa, \& Tahir, 2012). This relationship is 'almost' common in everyday accident scenario in Malaysia. As we all may agree that, the human is a complex living organism. The driving activity also involves complex motor components such as eyehand-coordination. Drivers who fail to organize and interact with the machine and environment may lead to road traffic injury (RTI). This made the human error as an important ergosystem component that needs to be further investigated.

Many studies had proven that human factor was identified as a significant contribution to RTA. Many interventions such as increasing the amount of summons which aims to educate the drives had seen no changes in driver's behavior. This could be proven by the number of accident and fatality each year remain stagnant. Programs focusing on attitude change and risk taking behavior have a better potential in addressing the fundamental cause of RTA. The question arose either the existing driving syllabus and licensing process addresses psychological and physiological domains to be a fit driver? Does the syllabus and training address sufficient knowledge, affective, psychomotor and soft skills to the drivers? Does it measurable? It may need to be reviewed and transform into a new format. What if the license that we have does not prepare us to be a fit, safe and health drivers? Then, we may allow risky and reckless drivers on the road. This will increase the risk of RTA and fortunately people may 'escape' the accident just only by chance.

Many RTA happens due to secondary factor or simply called as somebody mistake. This factor usually happens unexpectedly. For example, children crossing the road without any notice, other drivers/road users running the red light, turning without giving any signal, etc. This usually contributes to a fatal accident. To avoid this potential accident, drivers must be alert at all time. The factor of alertness usually is a combination of few other mental components such as cognitive, time respond, stress, and mental status. However, there is no specific characteristic of ideal or low-risk drivers have been developed locally. Dou to the complexity of the traffic demographic and mechanism, this study was embarked into two main objectives. The first objective of this study was to investigate the specific behaviour respond among accident victims through in-one-to-one depth interview. The second objective was to translate the themes and subthemes into an appropriate licensing process which perhaps will enable the government to monitor, rehabilitate and maintain safes drivers on the road.

\subsection{Methodology}

Describe This study limit the investigation based on five major risk factors as stated in the global status report on road safety 2013 by WHO; speed, drink-driving, helmet, seat belt, child restraint and other six offences that lead to maximum penalties (Road Transport Act 1987): exceeding the speed limit, involved in a traffic accident, disobey stop signal - red light, 
overtaking at double line, overtaking others in the queue and using an emergency lane/left lane. Since some factors such as drink-driving, wearing helmet and child restrain neither were nor meet with inclusion criteria, these factors will be excluded from this study. Another three factors such as mobile phone usage, signalling and respect to others was added based on researcher previous study (Isa et al., 2012). The interview questionnaire was adapted from Protection Motivation Theory, which was previously discussed by (Masuri et. al. 2014) as highlighted in table 1 combining with the conceptual framework in Figure 1.

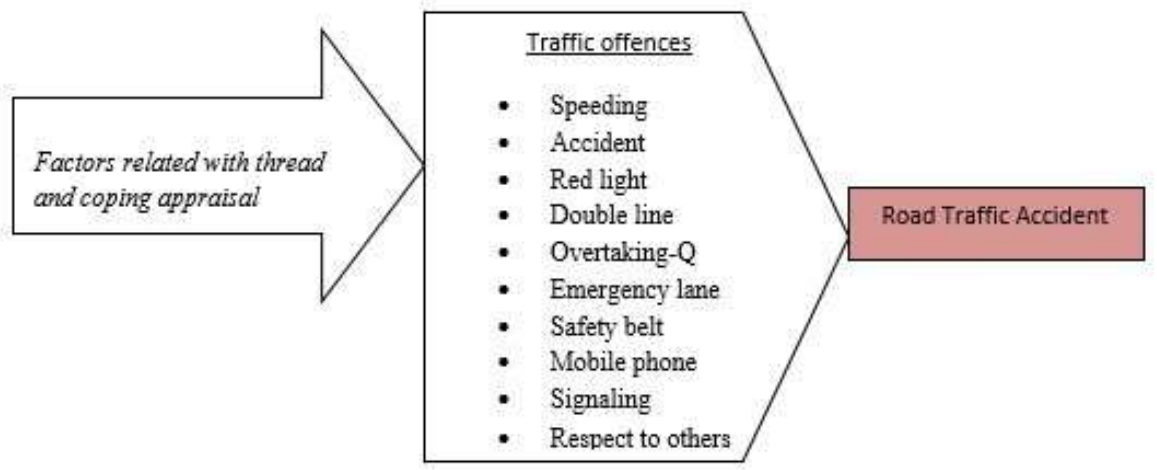

Figure 1: Research conceptual framework

(Source: Masuri, Dahlan, Danis, \& Isa, 2014).

\subsection{Results and Discussions}

The correct selection of models in intervention planning and program is very useful. The model that we used usually will become a guideline in the thinking process. The model also will help the practitioners to make an appropriate recommendation for the future. With regards to models related to health behavior studies, factors and argument highlighted usually focusing on how to influence people attitudes, behavior response and the intention to protect them from health thread. There were many health behaviors related models that available in the literature and Protection Motivation Theory (PMT) is one in the promising model that was used in the development of this study (Masuri et al., 2014). There were four factors that related in this model: perceived severity, perceived efficacy, perceived vulnerability and perceived self-efficacy (Boer \& Seydel, 1996; Cismaru, 2006; Egger, Spark, \& Lawson, 1990; Wu, Stanton, Li, Galbraith, \& Cole, 2005). The one-to-one interview was conducted to explore the respondent opinion regarding causes of RTA in their current environment. The interview components were focusing on the factors as stated on PMT (Masuri, Dahlan, Isa, et al., 2014). The semi-structured interview approach used were according to components in (Isa, et al., 2012) and the proposed model of an interview was based on (Chen, 2009; Lund \& Aarø, 2004; Wu, et al., 2005). From that interviews, all information gather was reorganized, and relevant themes were generated. ATLAS.ti software was used to manage all of the 
respondent data. The brief accident demographics as in Table 2.

Perceived vulnerability: the term perceived vulnerability refers to an individual's perception of the risk of a negative event occurring to them. For example, the interview session was focusing on the respondent possibility of having an accident on their daily trips. Respondent also was asked about their vulnerability on the other nine common offences that have been highlighted in Figure 1. Respondent respond was varied in many things including their personal feelings towards personal vulnerability. This interview revealed that, the higher the perceived vulnerability to a negative event, the higher the intention to follow the recommendations and it is similar with (Cismaru, 2006).

Perceived severity: for the purpose of investigating the perceived severity from all respondents, questions asked was focusing on to how serious is the implication of negative event towards their daily life. For example, the question regarding either they can manage with the penalties or not. The entire respondent agreed that they were not willing to get caught and been penalized. The result revealed that perceived severity varied from one respondent to another. This result also would like to suggest that, the higher the perceived severity of a health condition the higher the intention to follow the recommendations. During the interview, few provocative questions that centered to increased amount of fear towards traffic penalties were used. The use of fear concept has a strong communication about how serious is the consequences. This unpleasant message was successfully generated 'fear' among respondent. Fear is a very important component in PMT. Fear communication can influence cognitions, attitudes, behavior intentions and health behavior. Fear will act as a drive that motivates trial and error behavior (Boer \& Seydel, 1996).

Perceived response efficacy: refers to how the respondent believes that the recommended behavior will effectively reduce or eliminate the risk. Respondent was asked about their perception of good driver's behavior in reducing the risk of an accident. From all ten traffic offences asked, the result varied from one and another. Few respondents agreed that good drivers will always maintain their good driving behavior. On the other hand, law enforcement is the best method to control driver's behavior. In this case, the centre of argument was focusing on what behavior could avoid from all of the offences would significantly reduce chances to cause an accident. A few suggestions on how to avoid from those ten offences have been highlighted during this interview. The interview also revealed that, more positive respond resulting from the effective of health recommendations. Some of them also agreed that good drivers also need to be monitor.

Perceived self-efficacy: the final part of the interview was focusing on the respondent believe that they have the ability to perform the recommended behavior. The result shows that more positive responses from the highest level of perceived self-efficacy and this result supported the previous work by (Egger, et al., 1990), the person with strong sense of selfefficacy will be able to overcome any barrier. The respondent feels that they can avoid all offences, more likely they will engage in healthy behaviour. In conclusion, all respondents have agreed that it is possible to avoid accident in the future. What they need to do is to be more careful in the future. They were also agreed that all mistakes or offences bring significant chance for life and death. This variety of respond shows that all respondents were 
different in ability to control and influence their health.

Table 2 shows the brief accident demographic data from all seven respondents. There were seven $(n=7)$ respondent were interviewed. Their age range was between 22 to 46 years old and frequently travelling on urban area. There was only one respondent who had an accident without involving other vehicles. The environment which that accident happened was varied from day to night and clear to raining.

Table 3 shows the summary of the major and subthemes emerged from the interview. Major themes highlighted were based on the most repeated and agreeable among all respondents. The sub-themes were any other information may not agreed or raised by all but found to be significant and relevant in supporting the major theme.

Table 2: Accident demographics data

\begin{tabular}{|c|c|c|c|c|}
\hline Respondent & $\begin{array}{l}\text { Collision } \\
\text { involved }\end{array}$ & Location & $\begin{array}{l}\text { General } \\
\text { causes }\end{array}$ & $\begin{array}{c}\text { Accident } \\
\text { mechanism }\end{array}$ \\
\hline Male 1 & Car vs car & $\begin{array}{l}\text { Corner one } \\
\text { lanes }\end{array}$ & Poor visibility & Front-to-front \\
\hline Male 2 & $\begin{array}{l}\text { Motorcycle vs } \\
\text { car }\end{array}$ & $\begin{array}{l}\text { Corner two } \\
\text { lanes }\end{array}$ & $\begin{array}{l}\text { Car entered } \\
\text { motorcycle } \\
\text { lane }\end{array}$ & Side by side \\
\hline Male 3 & Car & $\begin{array}{l}\text { Corner one } \\
\text { lanes }\end{array}$ & Over speeding & Off course \\
\hline Male 4 & Motorcycle & $\begin{array}{l}\text { Corner one } \\
\text { lanes }\end{array}$ & Pitholes & Slide \\
\hline Male 5 & $\begin{array}{c}\text { Motorcycle vs } \\
\text { 4wd }\end{array}$ & $\begin{array}{l}\text { Straight } \\
\text { two lanes }\end{array}$ & $\begin{array}{l}\text { 4wd changing } \\
\text { lane without } \\
\text { signal }\end{array}$ & $\begin{array}{l}\text { Motorcycle to right } \\
\text { drivers side }\end{array}$ \\
\hline Male 6 & Car vs car & $\begin{array}{l}\text { Straight } \\
\text { one lanes }\end{array}$ & Over speeding & Front-to-front \\
\hline Female 1 & $\begin{array}{c}\text { Car vs lorry and } \\
\text { car }\end{array}$ & $\begin{array}{l}\text { T junction, } \\
\text { straight two } \\
\text { lanes }\end{array}$ & $\begin{array}{c}\text { Poor visibility } \\
\text { of the car due } \\
\text { to incoming } \\
\text { lorry }\end{array}$ & $\begin{array}{l}1 \text { st drivers side } \\
\text { with } 2^{\text {nd }} \text { car front }\end{array}$ \\
\hline Male 7 & $\begin{array}{l}\text { Motorcycle vc } \\
\text { car }\end{array}$ & $\begin{array}{l}\text { Straight } \\
\text { two lanes }\end{array}$ & $\begin{array}{l}\text { Car making U } \\
\text { turn at } \\
\text { prohibited } \\
\text { area and not } \\
\text { using signal }\end{array}$ & $\begin{array}{l}\text { Motorcycle to right } \\
\text { drivers side }\end{array}$ \\
\hline
\end{tabular}

Table 3: Themes emerged according to respondent response (translated into English)

Question

Does (all 10 traffic offences) can cause accident?

Can you manage with the summons or penalties?

(All 10 traffic offences) will limit my social life.
Major themes

Self attitude

Driving skills

Value for money

Live is priceless

Good citizen and good drivers
Sub themes

Common mistake Lack of knowledge Good drivers follow rules Law enforcement Good drivers follow rules 
In your opinion, does avoiding (all 10 traffic offences) helps prevent accident?

To what extend are you capable to avoid (all 10 traffic offences)?

\section{Discipline \\ Self judgment}

Self motivation and personal belief Driving skills and experience Rehabilitation or retraining.
Self motivation Anger management Patience and respect to others

Penalties and summon

Family and friends

Monitoring system/reevaluation Fatality.

\subsection{Construction of PreSiM}

The construction of this model starts with thematic classification and analysis. All text, phrase and words that have similar meaning were position into a related group. Cut and paste approach in Atlas.ti was used during this process. The meaning than analyze and any major themes and subthemes were drawn into a model. All subthemes that support the major themes were cross check for any overlapping. The major themes that emerge from those interviews were divided into four categories: screening, correction, reassessment, and maintenance. Theme number one and three were combined into the first stage and renamed as prevention and screening. The term correction was renamed into rehabilitation and was placed into the second stages. As part of an ongoing monitoring process, the theme maintenance was maintained at the last stage of the model. All segments 'work' as dynamic and this can be viewed through the arrows that were highlighted. Table 3 shows the themes and subthemes emerge from interviews conducted Table 3).

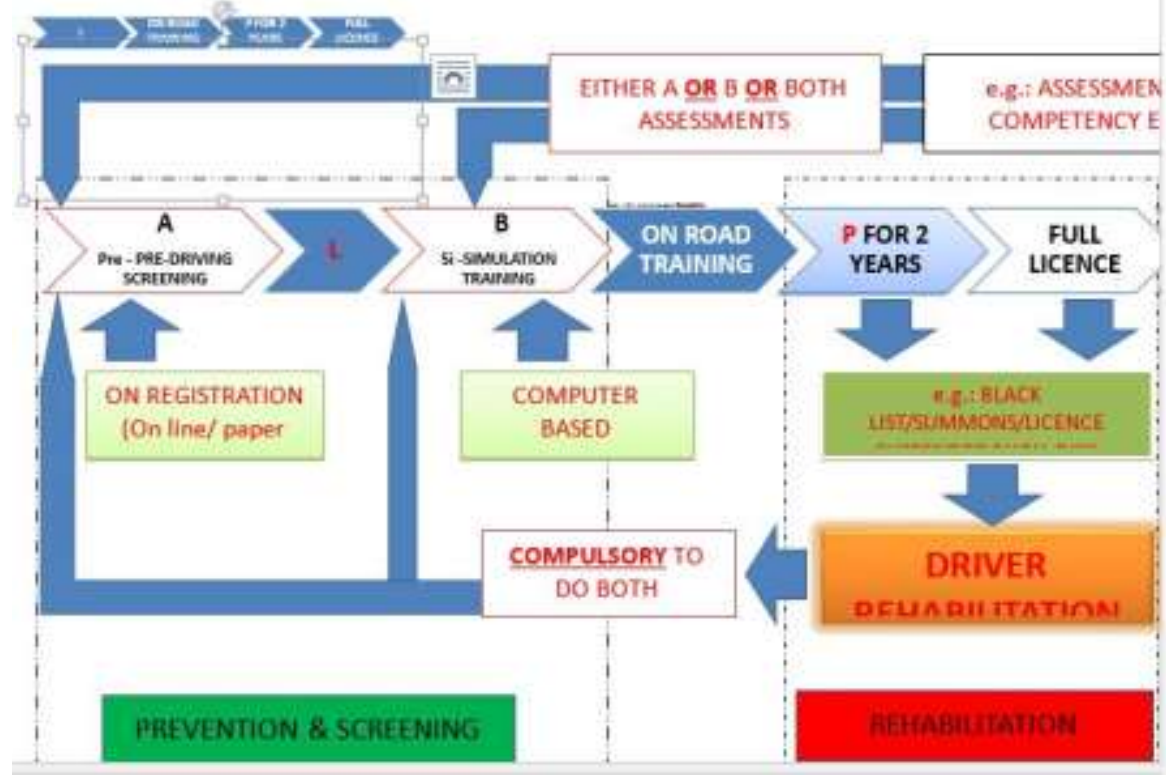

Figure 2 
Figure 2a shows the current licensing process in Malaysia. It is compulsory for each of the registered candidate to go through all of the licensing stages. The proposed model as in Figure $2 b$ still maintaining the current process, yet introducing three control elements namely; prevention \& screening, rehabilitation, and maintenance. In general, all competent, qualified drivers will only need to go through the maintenance process. On the other hand, the highrisk drivers may need to go through one or two of the control elements as illustrated below. High-risk drivers will need to go through the most 'severe' process where it is compulsory for them to go through re-evaluation process and rehabilitation program.

\subsection{Prevention and screening}

In general, this stage can be divided into two cycles with a different set of purposes. The first aim of this stage is to assist an individual to screen their personal ability to enrol for a full licensing program. Participant which successful in this stage should be able to understand and identify their readiness to enrol into the next steps. For the purpose of assessment and prevention program, the aim would be to monitor their current skills in controlling and manoeuvring their vehicles. The pre-driving screening and reassessment will involve the following components; an off-road test, paper-based or on line test and behavior and attitude self-evaluation.

\subsection{Rehabilitation}

This stage is critical for drivers with $\mathrm{P}$ or full license. Any high-risk drivers at this stage will be sent for rehabilitation. At this second stage, drivers who had to summon or had involved with traffic offences will need to go through a rehabilitation program. The rehabilitation stage will involve the following components; driving rehabilitation program, support group, module or exam based assessment and psychological support.

\subsection{Maintenance}

The reevaluation stage is focusing on the maintenance of good and competent drivers. At this stage, qualified drivers were expected to self-reevaluate their driving performance. Any support needed from other organization should be offered at this stage. For example, drivers who experience accident and trauma may request for special assistant from other health professionals. The maintenance stage consists of the following components; reevaluation of driver's competency level, medical record, family and emotional support and other psychological support. This model has highlighted the important of monitoring components along the licensing process. It was also recommend introducing reassessment and rehabilitation as part of the maintenance process. Even though maintenance may not be able to change driver's behavior, however, this study belief that good screening method and law enforcement will shape better drivers in the future. Either it was rural or urban, all respondent have agreed that drivers behavior is the major causes of road traffic accident in Malaysia. They also suggested that driver's competency should be reassessed in the future. To date, this model has been submitted to the Land Public Transport Commission Malaysia (SPAD) for a review. The implementation of this model may need good support from the Malaysian 
government. At the same time, Malaysian should also take an active move to change their driving behavior align with Malaysia development towards a developed country. The slogan of 'first class facility, third class mentality' should be changed to compensate the status of a developed country by the year of 2020 .

\subsection{Conclusion}

This study concluded that cognitive and psychological components have a high potential to be entrenched in the current licensing system. This model of intervention may help to reduce the potential of road traffic accident due to disorientation. This proposes model to address the important of rehabilitation and maintenance components. These components were believed will help the road users to orientate them to the current environment and understand their cognitive and psychological limitations. However, this model is needed to be further tested.

\section{Acknowledgement}

This study would like to thank the Research Management Institute (RMI) and all staff of the Faculty of Health Sciences UiTM Puncak Alam for continuous support in staff research and development. This study was funded by (600-RMI/FRGS 5/3 (118/2013).

\section{References}

APA Al-Naggar, R. A., Bobryshev, Y. V., \& Mohd Noor, N. A. B. (2013). Lifestyle practice among Malaysian university students. Asian Pacific journal of cancer prevention, 14(3), 1895-1903.

Boer, H., \& Seydel, E. R. (1996). Protection Motivation Theory. In M. Conner \& P. Norman (Eds.), Predicting Health Behaviour: research and practice with social cognition models (pp. 95-120). Buckingham: Open University Press.

Chen, C.-F. (2009). Personality, safety attitudes and risky driving behaviors-Evidence from young Taiwanese motorcyclists. Accident Analysis \& Prevention, 41(5), 963-968. doi: http://dx.doi.org/10.1016/j.aap.2009.05.013

Cismaru, M. (2006). Using Protection Motivation Theory to Increase the Persuasiveness of Public Service Communications. University of Regina Retrieved from http://www.uregina.ca/sipp/documents/pdf/PPP40.pdf.

Egger, G., Spark, R., \& Lawson, J. (1990). Health promotion strategies \& methods. New South Wales: McGraw-Hill Book Company.

Isa, K. A. M., Masuri, M. G., Abd Aziz, N. A., Isa, N. N. M., Hazali, N., Tahir, M. P. M., et al. (2012). Mobile Phone Usage Behaviour while Driving among Educated Young Adults in the Urban University. Procedia - Social and Behavioral Sciences, 36(0), 414-420. doi: http://dx.doi.org/10.1016/.jsbspro.2012.03.045

Lund, J., \& Aarø, L. E. (2004). Accident prevention. Presentation of a model placing emphasis on human, structural and cultural factors. Safety Science, 42(4), 271-324. doi: 10.1016/s0925-7535(03)00045-6 
Masuri, M. G., Dahlan, A., Danis, A., \& Isa, K. A. M. (2014). Public participation in shaping better Malaysian's road society in the future. Procedia - Social and Behavioral Sciences, in print.

Masuri, M. G., Dahlan, A., Isa, K. A. M., Danis, A., Natar, A. K. M., Thanapalan, C. K. K., et al. (2014). The Use of Protection Motivation Theory (PMT) in developing Malaysian Driver's Attitude Evaluation. Paper presented at the CHUSER2014, Penang Malaysia in press.

Masuri, M. G., Isa, K. A. M., \& Tahir, M. P. M. (2012). Children, Youth and Road Environment: Road Traffic Accident. Procedia - Social and Behavioral Sciences, 38(0), 213-218. doi: http://dx.doi.org/10.1016/j.sbspro.2012.03.342

Masuri, M. G., Isa, K. A. M., Tahir, M. P. M., Hassan, H. F., Hassan, Z., Jamhuri, F. Z., et al. (2012). Behaviour Response among Health Sciences Students towards H1N1 Pandemic. Procedia - Social and Behavioral Sciences, 36(0), 77-86. doi: 10.1016/j.sbspro.2012.03.009

Mohammadi, G. (2011). Prevalence of seat belt and mobile phone use and road accident injuries amongst college students in Kerman, Iran. . Chinese Journal of Traumatology English Edition, 14(3), 165-169.

Pheasant, S. (1990). Bodyspace: anthropometriy, ergonomics and the design of work (2nd ed.). London: Taylor \& Francis Publisher.

Rakauskas, M. E., Ward, N. J., \& Gerberich, S. G. (2009). Identification of differences between rural and urban safety cultures. Accident analysis and prevention, 41(5), 931-937.

Shappell, S., \& Weigmann, D. (2013). Human Factors Investigation and Analysis of Accidents and Incidents: Encyclopedia of Forensic Sciences (2 ed.).

Wu, Y., Stanton, B. F., Li, X., Galbraith, J., \& Cole, M. L. (2005). Protection Motivation Theory and Adolescent Drug Trafficking: Relationship Between Health Motivation and Longitudinal Risk Involvement. Journal of Pediatric Psychology, 30(2), 127-137. 